\title{
Removal of Dye Toxicity from an Aqueous Solution Using an Industrial Strain of Saccharomyces Cerevisiae (Meyen)
}

\author{
Guilherme Dilarri • Érica Janaina Rodrigues de Almeida • Hengli Barbosa Pecora • \\ Carlos Renato Corso
}

Received: 1 April 2016 / Accepted: 4 July 2016 / Published online: 14 July 2016

(C) Springer International Publishing Switzerland 2016

\begin{abstract}
The use of synthetic dyes is commonplace in many industries, and the effluent is often dumped into the environment with no prior treatment. The aim of the present study was to analyze the use of an industrial strain of Saccharomyces cerevisiae (Meyen) for the removal of the textile dye Acid Blue 161 from an aqueous solution. Kinetic, isotherm, and thermodynamic models were created to evaluate the biosorption mechanisms. Fourier transfer infrared (FT-IR) spectroscopy was used to characterize and identify possible binding sites. A toxicity test was also performed using Artemia salina to analyze the degree of toxicity of the dye following treatment. The kinetic results demonstrated the occurrence of intraparticle diffusion in the yeast cells as the controlling mechanism of the sorption process. Biosorption followed the Langmuir model, except at $\mathrm{pH} 8.50$, when it fit the Freundlich model. The thermodynamic results demonstrate that the biosorption
\end{abstract}

\author{
G. Dilarri $(\bowtie) \cdot$ É. J. R. de Almeida • H. B. Pecora • \\ C. R. Corso \\ Department of Biochemistry and Microbiology, São Paulo State \\ University (UNESP), 24-A Avenue, $n^{\circ} 1515$, Postal Code: \\ 13506-900 Rio Claro, SP, Brazil \\ e-mail: dilarri@hotmail.com \\ É. J. R. de Almeida \\ e-mail: almeidaejr@gmail.com \\ H. B. Pecora \\ e-mail: hengli_barbosa@yahoo.com.br \\ C. R. Corso \\ e-mail: crcorso@rc.unesp.br
}

process is spontaneous and endothermic. The FT-IR analyses confirmed the occurrence of a chemical reaction in acid $\mathrm{pH}$, but physical adsorption only occurred at $\mathrm{pH}$ 8.50. The toxicity test showed that the use of the yeast biomass led to the complete removal of toxicity from the dye solution, demonstrating the effectiveness of the biosorption process in the treatment of effluents contaminated with these compounds.

Keywords Azo dyes - Bioremediation - Biosorption · Chemisorption - Toxicity test $\cdot$ Yeast

\section{Introduction}

Environmental pollution is one of the major problems of our time and leads to physical, chemical, and biological changes in the environment that compromise the quality of soil, air, and water. Due to industrial activities, bodies of water are the most affected components of the environment. The textile, leather, cosmetic, paper, printing, plastic, and other industries use synthetic dyes to color their products (Sharma et al. 2011), and the effluents of these processes are discarded, with the frequent dumping of chemical pollutants directly into aquatic ecosystems with no prior treatment (Attia et al. 2008). Once in the environment, dyes and derivatives may exhibit toxicity with mutagenic and carcinogenic effects in organisms (Toor et al. 2006). Dyes also affect nutrient and water cycles and may cause allergic dermatitis and skin sensitivity (Ghazi Mokri et al. 2015). 
Textile industries are the main source of bulky waste containing dyes (Gong et al. 2007). The textile sector has a share of two thirds of the total dyestuff market (Safariková et al. 2005) and is responsible for majority of production, usage, and disposal of effluents containing dyes. More than $50 \%$ of all dyes used in the textile sector are the azo type (Behnajady et al. 2006). These dyes are characterized by azo groups $(-\mathrm{N}=\mathrm{N}-)$ linked to aromatic species in their chemical structure. Such chemical conformation makes them more toxic and difficult to degrade in the environment.

Techniques have been proposed to treat effluents contaminated with dyes, such as flocculation, ozonation, and photodegradation (Farah et al. 2007). However, the high costs of these treatments underscore the need for alternative methods. Biological treatment involving dye-degrading microorganisms has been studied and proposed as an alternative (Priya et al. 2015). Still, degradation often requires a long time before achieving satisfactory results and can sometimes result in by-products that are even more toxic than the dye itself (Almeida and Corso 2014). The effluent treatment itself is not enough to confirm the effectiveness of the techniques; therefore, post-treatment toxicity evaluation is recommended (Immich et al. 2009). Another problem relates to dye-degrading bacteria and fungi that are often opportunistic pathogens, such as Aspergillus niger (Almeida and Corso 2014), Candida albicans (Vitor and Corso 2008), and Pseudomonas aeruginosa (Jadhav et al. 2010).

In this context, biosorption using a microorganism biomass is a viable alternative. The advantages of this process include the lower cost, the elimination of ecological risk stemming from the recovery of toxic compounds, the possibility of treating large volumes of effluents, and the fact that the source material is inexhaustible (Suteu et al. 2013). Another advantage of using the microbial biomass as an adsorbent is the use of dead cells as biomass, which in addition to increasing efficiency in adsorption, also ensures that if the biomass enter in contact with the environment does not occur any damage (Srinivasan and Viraraghavan 2010). Saccharomyces cerevisiae (Meyen), popularly called Baker's yeast, is present in different technological activities and produces high yields of biomass for use on an industrial scale. Moreover, this microorganism is inexpensive, safe, easily grown, and readily available (Farah et al. 2007). But this industrial strain of $S$. cerevisiae (Meyen) has not yet been tested in textile dyes as a possible adsorbent biomass.

The aim of the present study was to analyze the biosorption potential of an industrial strain of S. cerevisiae (Meyen) for the removal of the azo textile dye Acid Blue 161. Kinetic, isotherm, and thermodynamic models were used to determine the sorption mechanisms. Fourier transfer infrared (FT-IR) spectroscopy was used to characterize and identify possible binding sites. A toxicity test was also performed using Artemia salina to analyze the degree of toxicity of the dye following treatment and thereby evaluate the potential use of S. cerevisiae (Meyen) biomass in the treatment of effluents contaminated with these materials.

\section{Materials and Methods}

\subsection{Dead Biomass of S. cerevisiae (Meyen)}

An industrial strain of $S$. cerevisiae (Meyen), Baker's yeast, was obtained in freeze-dried form from the company J Macedo S/A-Brazil. One thousand milligrams of freeze-dried yeast biomass were dissolved in $100 \mathrm{~mL}$ of saline solution $(0.85 \% \mathrm{NaCl})$. The solution was autoclaved at $393.15 \mathrm{~K}$ at $1 \mathrm{~atm}$ for $20 \mathrm{~min}$ and then centrifuged for $30 \mathrm{~min}$ at $4000 \mathrm{rpm}$ to separate the medium from the cells. The cells were left to dry for $10 \mathrm{~h}$ at $353.15 \mathrm{~K}$. The biomass of dried cells were weighed again and stored in closed bottles in the dark.

\subsection{Dye}

Water-soluble Acid Blue 161 (AB 161) (purity $40 \%$; molecular mass $416.39 \mathrm{~g} \mathrm{~mol}^{-1} ; \lambda_{\max }=603.82 \mathrm{~nm}$; $\mathrm{pH}$ 4.50) was obtained from the Aldrich Chemical Company Inc. (Chemical Abstract Service (CAS) number 12392-64-8). The dye stock solution was prepared by diluting $1 \mathrm{~g}$ of powdered dye in $1 \mathrm{~L}$ of distilled water.

\subsection{Biosorption Kinetic Studies}

Kinetic studies were performed using $20 \mathrm{~mL}$ of the dye solution with a concentration of $100 \mu \mathrm{g} \mathrm{mL}^{-1}$ in 100 -mL Erlenmeyer flasks at $\mathrm{pH} 4.50$. Fifty milligrams (dry weight) of yeast biomass were placed in contact with the dye solution for $3 \mathrm{~h}$ at $293.15 \mathrm{~K}$ with constant agitation at $40 \mathrm{rpm}$. Aliquots of the solution were 
removed every 30 min for analysis in a UV-vis spectrophotometer (Shimadzu, Model 2401-PC), with scanning from 200 to $800 \mathrm{~nm}$ in a quartz cuvette measuring $10 \mathrm{~mm}$ in width. Before each UV-vis spectrophotometric analysis, the sample was centrifuged for $20 \mathrm{~min}$ at $4000 \mathrm{rpm}$. The amount of sorbed dye was calculated using Eq. 1:

$q e=\frac{V \cdot(\mathrm{Co}-\mathrm{Ce})}{W}$

in which $W$ is weight $(\mathrm{mg}), V$ is volume $(\mathrm{mL}), q e$ is the quantity of dye sorbed by the yeast biomass $\left(\mu \mathrm{g} \mathrm{mg}^{-1}\right)$, $C o$ is the initial concentration of dye $\left(\mu \mathrm{g} \mathrm{mL}^{-1}\right)$ and $C e$ is the remaining concentration $\left(\mu \mathrm{g} \mathrm{mL}^{-1}\right)$.

For a better interpretation of the data, the pseudo-first order Lagergren (1898) (Eq. 2) and pseudo-second order Ho and McKay (1998) (Eq. 3) mathematical models were employed.

$\ln \left(q e^{-q t}\right)=\ln q e^{-k l . t}$

and

$\frac{t}{q t}=\frac{1}{k s \cdot q e^{2}}+\frac{t}{q e}$

in which $t$ is time (min), $k l$ is the pseudo-first order adsorption rate constant $\left(\mathrm{min}^{-1}\right)$, qt is the amount of dye sorbed at time $t\left(\mu \mathrm{g} \mathrm{mg}^{-1}\right)$ and $k s$ is the pseudosecond order rate constant $\left(\mathrm{mg} \mu \mathrm{g}^{-1} \mathrm{~min}^{-1}\right)$. The linear regression graph of pseudo-first order plot $(\ln (q e-q t)$ vs. $t$ ) and pseudo-second order plot (t/qt vs. $t$ ), was made to determine the $k l, k s$, and qe values.

Kinetic processes are often controlled by diffusion. External mass transfer can occur during solid-liquid adsorption processes, in which the adsorbate is diffused internally in the adsorbent. This process is known as intraparticle diffusion (Aravindhan et al. 2007). The equation proposed by Weber and Morris (1963) (Eq. 4) was used to determine the occurrence of this diffusion process.

$q t=K d i \cdot t^{0,5}+C$

in which $C$ is a constant related to the thickness of the diffusion layers $\left(\mu \mathrm{g} \mathrm{mg}^{-1}\right.$ ) and $K d i$ is the constant intraparticle diffusion rate $\left(\mathrm{mg} \mu \mathrm{g}^{-1}\left(\min ^{0.5}\right)^{-1}\right)$.

Intraparticle diffusion can occur simultaneously with surface adsorption and may not be the driving factor of the reaction (Saber-Samandari and Heydaripour 2015). The equation developed by Boyd et al. (1947) (Eq. 5) was used to determine whether intraparticle diffusion was the controlling biosorption process.

$F=\frac{q t}{q e}$

and

$B t=-0.4977-\ln (1-F)$

in which $F$ is the fraction of solute adsorbed at any time and $B t$ is a mathematical function of $F$.

If the Boyd plot (Bt vs. $t$ ) is linear and the line passes through the origin, then intraparticle diffusion is the dominant process of biosorption (Aravindhan et al. 2007). By using Boyd's second model (Eq. 6), we could calculate the coefficients of intraparticle diffusion of the dead yeast biomass.

$D i=\frac{r^{2} \cdot B b}{\pi^{2}}$

$B b$ is calculated from the graph of $B t$ as a function of $t$; $D i$ is the effective diffusion coefficient $\left(\mathrm{cm}^{2} \mathrm{~s}^{-1}\right)$ of $\mathrm{AB}$ 161 dye in the biomass, and $r$ is the average yeast cell radius $(0.00025 \mathrm{~cm})$.

\subsection{Isotherm Studies}

The same volume and concentration of dye solution were used in the isotherm studies as those employed in the kinetic studies. To analyze the different biosorption mechanisms, the $\mathrm{pH}$ of the dye solution was varied $(2.50,4.50,6.50$, and 8.50), with a constant temperature of $293.15 \mathrm{~K}$ and agitation at $40 \mathrm{rpm}$. The dry weight mass of the yeast was 20 to $60 \mathrm{mg}$.

The Langmuir and Freundlich models were used to analyze the data. The Langmuir model (1918) (Eq. 7) states that a chemical adsorbate species will interact with the surface of the adsorbent with a finite number of binding sites forming a monolayer (Podkoscielny and Nieszporek 2011).

$\frac{C e}{q e}=\frac{1}{l . q m}+\frac{C e}{q m}$

in which $l$ is the affinity of the adsorbent and adsorbate $\left(\mathrm{mL} \mathrm{mg}^{-1}\right)$ and $q m$ is the maximum quantity of adsorbate adsorbed $\left(\mu \mathrm{g} \mathrm{mg}^{-1}\right)$.

The Celqe vs. Ce chart allows the determination of the $q m$ and $l$ values. The equation proposed by McKay et al. (1982) (Eq. 8) was used to determine the separation factor of the Langmuir equation 
(defined as $R l$ ) and discover whether biosorption is favorable or unfavorable.

$R l=\frac{1}{1+l \cdot C o}$

If $R l=0$ the adsorption to be irreversible, $R l=1$ linear, $R l>1$ unfavorable, and $0<R l<1$ favorable (McKay et al. 1982).

The Freundlich model (1906) (Eq. 9) proposes that binding sites are occupied exponentially, forming multiple layers (Saber-Samandari and Heydaripour 2015). It is therefore supposed that the surface of the adsorbent is heterogeneous, with several binding sites that are occupied in decreasing order according to their intensity of interaction with the adsorbate.

$\ln q e=\ln K f+\frac{1}{n f} \cdot \ln C e$

$n f$ is the adsorption constant, and $K f$ is the constant of solid adsorption capacity $\left(\mathrm{mL} \mathrm{mg}^{-1}\right)$. By plotting the linear regression graph of $\ln q e$ vs. $\ln C e$, it is possible to determine the $n f$ and $K f$ values.

Thermodynamic analyses were conducted by varying the temperature from 283.15 to $323.15 \mathrm{~K}$. The dye solution was tested at $\mathrm{pH} 4.50$, using $50 \mathrm{mg}$ (dry weight) of yeast. The equation proposed by van't Hoff (Eq. 10) was used to analyze the results obtained in the thermodynamic studies.

$\ln K t s=\frac{\Delta s}{R g}-\frac{\Delta H}{R g} \cdot \frac{1}{T}$

and

$K \quad t s=\frac{q e}{C e}$

in which $R g$ is the universal gas constant $\left(8.314 \mathrm{~J} \mathrm{~mol}^{-1}\right.$ $\left.\mathrm{K}^{-1}\right), T$ is temperature $(\mathrm{K}), K t s$ is the equilibrium constant during temperature variation $\left(\mathrm{mol} \mathrm{g}^{-1}\right), \Delta s$ is entropy, and $\Delta H$ is enthalpy.

The lnKts vs. (1/T) graph allows the determination of the enthalpy and entropy values. Equation 11 was employed to calculate the Gibbs free energy $(\Delta G)$.

$\Delta G=\Delta H-(\Delta S . T)$

All isotherm and kinetic experiments were performed in triplicate. We confirmed the mathematical model adequate fit to data by standard deviation $(S D)$ values from Eq. 12. Smaller values of $S D$ imply more accurate estimations, as described by Gholizadeh et al. (2013).

$S D=\sqrt{\frac{1}{N-1} \sum_{i=1}^{N}\left(\frac{\text { Qie-Qic }}{\text { Qie }}\right)^{2}}$

in which Qie and Qic $\left(\mu \mathrm{g} \mathrm{mg}^{-1}\right)$ are experimental and calculated mass of dye adsorbed by yeast biomass, and $N$ is the number of measurements made.

\subsection{FT-IR Spectrophotometry Analysis}

The yeast and the dye were analyzed before and after biosorption using a FT-IR spectrophotometer (Shimadzu Model 8300). Salt pellets were prepared using $1 \mathrm{mg}$ of sample and $149 \mathrm{mg}$ of $\mathrm{KBr}$. The samples were dried at $378.15 \mathrm{~K}$ for $24 \mathrm{~h}$ and then compressed at $40 \mathrm{kN}$ for $5 \mathrm{~min}$ to form pellets. Thirty-two scans were performed at a range of 400 to $4000 \mathrm{~cm}^{-1}$, with $4 \mathrm{~cm}^{-1}$ of resolution for each sample. The chemical structures and graphs for this study were made using the Origin 6.10 and $\mathrm{ACD} / \mathrm{ChemSketch} \mathrm{software} \mathrm{programs.}$

\subsection{Toxicity Test with Microcrustacean A. salina}

The test described by Varó et al. (1998) was used to determine the lethal concentration $\left(\mathrm{LC}_{50}\right)$ of $\mathrm{AB} 161$ dye for A. salina. Toxicity was analyzed based on the mortality of $A$. salina larvae after $48 \mathrm{~h}$ of exposure to the dye solution, with the determination of $\mathrm{LC}_{50}$ and $\mathrm{LC}_{100}$ values. A. salina larvae were kept at temperatures of 293.15 and $303.15 \mathrm{~K}$ in synthetic seawater with $3.2 \%$ salinity and $\mathrm{pH}$ 6.50. The larvae used in the toxicity test were selected through positive phototropism, as described by Almeida and Corso (2014). Selected larvae were exposed to different concentrations of $\mathrm{AB} 161$ dye in a static system for $48 \mathrm{~h}$. A sample with no dye and one with a known concentration of sodium dodecyl sulfate (SDS) were used as the controls. The test was considered valid when the survival percentage from the control (synthetic seawater) was greater than or equal to $90 \%$, and the $\mathrm{LC}_{50}$ for SDS was within the range of sensitivity provided (Parra et al. 2001).

To test the toxicity of the solution after the biosorption process, $100 \mathrm{~mL}$ of a dye solution were used with the same concentration as the $\mathrm{LC}_{50}$ at $\mathrm{pH} 6.50$ at a temperature of $303.15 \mathrm{~K}$. A total of 100,500 and $1000 \mathrm{mg}$ of dry S. cerevisiae (Meyen) biomass were 
used. During the biosorption process, the solution was under constant agitation at $40 \mathrm{rpm}$. After $3 \mathrm{~h}$, the yeast biomass was separated from the solution, and A. salina was placed into contact with this solution for $48 \mathrm{~h}$ without stirring. The numbers of living and floating organisms were then counted. The test was performed with three replications, and the results were determined using the same proposed model for $\mathrm{LC}_{100}$ and $\mathrm{LC}_{50}$ (Varó et al. 1998).

\section{Results and Discussion}

\subsection{Biosorption Kinetic Studies}

The kinetic studies showed that $q e_{(\exp )}$ of the dead yeast cells reached equilibrium at $150 \mathrm{~min}$ (Fig. 1), which is therefore the maximum time for the biosorption reaction of the adsorbent.

Table 1 displays the results of kinetics models, which indicate that yeast biomass best fits the pseudo-second order model, with a correlation relatively close to 1 . The $q e_{\text {(cal) }}$ values of the pseudo-second order were also closer to the $q e_{(\exp )}$, confirming the goodness-of-fit of the model. This result is consistent with the heterogeneous nature of the cell wall of $S$. cerevisiae, as the pseudo-second order model has optimal settings for adsorbents with heterogeneous sites (Li et al. 2008).
The finding is also indicative of the occurrence of chemisorption (Guerra and Airoldi 2009).

The $q t$ vs. $t^{0.5}$ graph (Fig. 2) shows two linear regions representing the diffusion boundary layer, followed by intraparticle diffusion in macro pore (Ho and McKay 1998). This result demonstrates the occurrence of intraparticle diffusion and indicates that the yeast biomass only reaches adsorption equilibrium when diffusion occurs in the macro pore layer.

The macro pore layer $\left(K d i=0.009 \mu \mathrm{g} \mathrm{mg}^{-1}\right.$ $\left.\left(\min ^{0.5}\right)^{-1}, C=1.147 \mu \mathrm{g} \mathrm{mg}^{-1}, R^{2}=0.885, S D=0.114\right)$ showed a $K d i$ value lower than the first boundary layer $\left(K d i=0.138 \mu \mathrm{g} \mathrm{mg}^{-1}\left(\min ^{0.5}\right)^{-1}, C=0.073 \mu \mathrm{g} \mathrm{mg}^{-1}\right.$, $R^{2}=0.972, S D=0.131$ ), indicating that sorption occurs rapidly in the yeast biomass by intraparticle diffusion. When the constant of thickness of the diffusion layer is less than $0.50 \mu \mathrm{g} \mathrm{mg}^{-1}$, the material exhibits no resistance to intraparticle diffusion (Guerra and Airoldi 2009). This confirms that first boundary layer did not have resistance to intraparticle diffusion, indicating that it controlled the sorption process.

The Boyd plot (Bt vs. $t$ ) (Fig. 3) was a straight line that went through the origin, confirming that diffusion is the dominant process in biosorption using dead S. cerevisiae (Meyen) cells. The results also indicate chemisorption. It can therefore be said that $\mathrm{AB} 161$ dye has high affinity for $S$. cerevisiae (Meyen) biomass.
Fig. 1 Graph of experimental adsorption kinetics

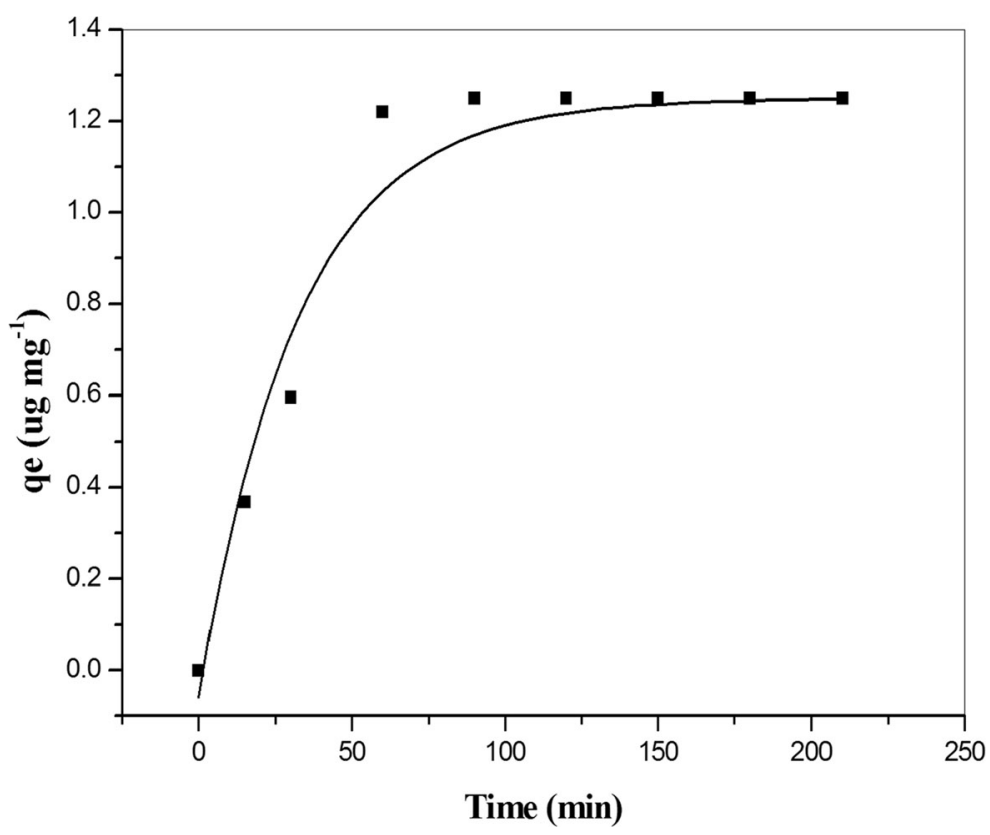


Table 1 Results of kinetic studies

\begin{tabular}{|c|c|c|c|c|c|}
\hline \multirow[t]{2}{*}{ Pseudo-first order } & $q e_{(\exp )}\left(\mu \mathrm{g} \mathrm{mg}^{-1}\right)$ & $k l\left(\min ^{-1}\right)$ & $q e_{(\mathrm{cal})}\left(\mu \mathrm{g} \mathrm{mg}^{-1}\right)$ & $R^{2}$ & SD \\
\hline & 1.248 & 0.010 & 0.820 & 0.827 & 0.570 \\
\hline \multirow[t]{2}{*}{ Pseudo-second order } & $q e_{(\exp )}\left(\mu g \mathrm{mg}^{-1}\right)$ & $k s\left(\mathrm{mg} \mu \mathrm{g}^{-1} \min ^{-1}\right)$ & $q e_{(\mathrm{cal})}\left(\mu \mathrm{g} \mathrm{mg}^{-1}\right)$ & $R^{2}$ & $\mathrm{SD}$ \\
\hline & 1.248 & 0.034 & 1.407 & 0.982 & 5.722 \\
\hline
\end{tabular}

Suteu et al. (2013) conducted studies on intraparticle diffusion with dead $S$. cerevisiae biomass and concluded that diffusion is not the driving force of the biosorption process. This likely occurred due to the low affinity between the dye tested and the cell wall of the yeast.

Through graphic pendant of Boyd plot (Bt vs. $t$ ), it was possible determine $B b$ value (0.0094). The $D i$ value was $5.952 \times 10^{-11} \mathrm{~cm}^{2} \mathrm{~s}^{-1}$, which means that only an outer binding site is interacting with the adsorbent (Singh et al. 2003).

\subsection{Isotherm Studies}

Isotherm studies allow the identification of interaction mechanisms in the biosorption process and characterize the process as either physical or chemical. The sorption and desorption equilibrium of a solid/solution interface also allows optimizing a biosorption process to increase its efficiency (Araujo et al. 2006).

The results of the isotherms indicate that biosorption best fit the Langmuir model, indicating the interaction of adsorbate with only a specific site on the adsorbent, forming a monolayer. When the dye solution was at $\mathrm{pH} 8.50$, however, biosorption fit the Freundlich model (Table 2).

Observing the $l$ values, adsorbate/adsorbent affinity decreased with the increase in $\mathrm{pH}$. The same was true for the $q m$ values, as an increase in $\mathrm{pH}$ led to a decrease in the maximum adsorption capacity of the yeast biomass. The $R l$ values indicate that all $\mathrm{pH}$ values tested were favorable to adsorption, but the $R l$ of the solution was highest at $\mathrm{pH} 8.50$, indicating a greater rate of desorption. It can therefore be said that more alkaline $\mathrm{pH}$ is unfavorable to biosorption.

Although the results of the isotherms do not fit the Freundlich model, with the exception of $\mathrm{pH} 8.50$, one can see that the values for the solid capacity sorption $(K f)$ decreased with the increase in $\mathrm{pH}$, thereby confirming the low sorption capacity at alkaline $\mathrm{pH}$ values. The adsorption constant values $(n f)$ were all less than 1 , indicating a lack of the occurrence of sideformation interactions or multiple layers (Annadurai
Fig. 2 Intraparticle diffusion graph

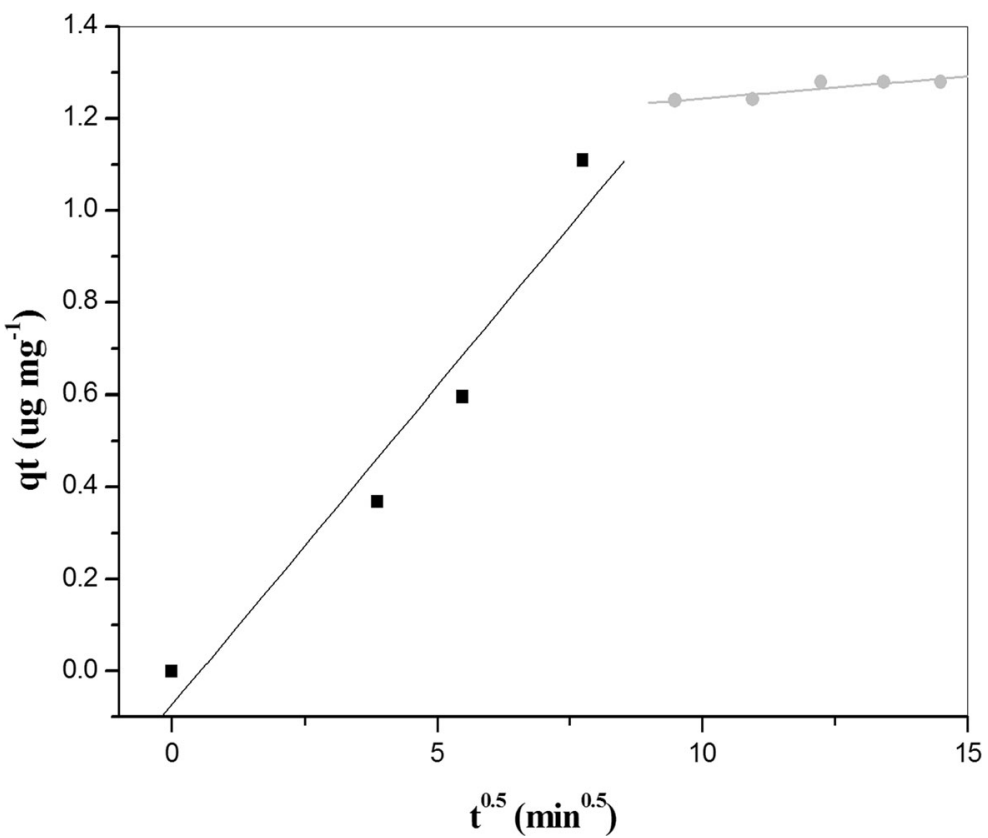




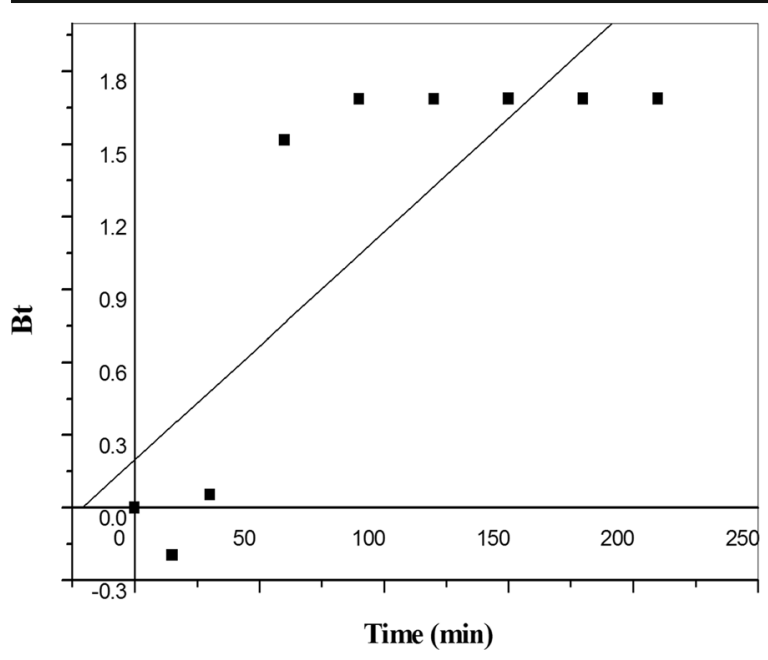

Fig. 3 Boyd function graph

et al. 2008). These results are in agreement with the data from the kinetic studies and Langmuir isotherm. The results of the Freundlich isotherm also indicate that biosorption at $\mathrm{pH} 8.50$ is likely a physical process.

Through the analysis of thermodynamic parameters, one can determine whether the biosorption process is spontaneous, exothermic, or endothermic (Fat'hi et al. 2014). The positive entropy value (Table 3 ) demonstrates randomness during biosorption. This indicates heterogeneous sites and likely corresponds to the heterogeneity of the yeast cell wall. The cell wall of $S$. cerevisiae is composed of chitin, mannoproteins, and glucans (Lipke and Ovalle 1998). Biosorption occurs at low intensities at heterogeneous sites and is predominantly stronger at a specific site (Suteu et al. 2013).

The enthalpy value was higher than $40 \mathrm{~kJ} \mathrm{~mol}^{-1}$, confirming that biosorption occurs through a chemical interaction between the adsorbate and adsorbent. This result is in agreement with the data obtained from the pseudo-second order model. Thus, one can say that chemisorption of the dye occurs due in the presence of
Table 3 Results of thermodynamic studies

\begin{tabular}{llll}
\hline $\begin{array}{l}\text { Temperature } \\
(\mathrm{K})\end{array}$ & $\begin{array}{l}\Delta G \\
\left(\mathrm{~kJ} \mathrm{~mol}^{-1}\right)\end{array}$ & $\begin{array}{l}\Delta S\left(\mathrm{~kJ} \mathrm{~mol}^{-1}\right. \\
\left.\mathrm{K}^{-1}\right)\end{array}$ & $\begin{array}{l}\Delta H \\
\left(\mathrm{~kJ} \mathrm{~mol}^{-1}\right)\end{array}$ \\
\hline 283.15 & 11.345 & 0.114 & 43.625 \\
293.15 & 10.205 & & \\
303.15 & 9.065 & & \\
323.15 & 6.785 & & \\
\hline
\end{tabular}

the $S$. cerevisiae (Meyen) biomass. The positive enthalpy values also indicate that biosorption is an endothermic process.

The Gibbs free energy values decreased as the temperature increased, indicating that biosorption of the dye by the $S$. cerevisiae (Meyen) biomass is a spontaneous reaction (Fat'hi et al. 2014). This result also confirms that the biosorption process is influenced by temperature, with the most efficient removal of the dye at a temperature of $323.15 \mathrm{~K}$.

According to Suteu et al. (2013), S. cerevisiae biomass begins to deteriorate at $318.15 \mathrm{~K}$, undergoing changes in sorption properties and is not recommended to use this or higher temperatures for the biosorption of dyes. However, this phenomenon was not observed in the present investigation. This divergence is likely due to the difference in the industrial strains of $S$. cerevisiae used in each study.

\subsection{FT-IR Spectrophotometric Analysis}

The $S$. cerevisiae (Meyen) biomass spectrum (Fig. 4) showed two intense peaks in the 1649 and $1540 \mathrm{~cm}^{-1}$ regions, which represent the binding of the amide group $\mathrm{R}-\mathrm{NH}-\mathrm{C}-\mathrm{O}-\mathrm{CH}_{3}$. The band at $1350 \mathrm{~cm}^{-1}$ is the stretching of the $-\mathrm{C}-\mathrm{NH}$ bond, probably by an amine group belonging to a chitin of the yeast cell wall. The peak in the $1234 \mathrm{~cm}^{-1}$ region shows the vibration of the $-\mathrm{C}=\mathrm{O}$ bond, which is another linking group in the chitin

Table 2 Results of isotherm constants at different $\mathrm{pH}$ values

\begin{tabular}{|c|c|c|c|c|c|c|c|c|c|}
\hline \multirow[t]{2}{*}{$\mathrm{pH}$} & \multicolumn{5}{|c|}{ Langmuir isotherm } & \multicolumn{4}{|c|}{ Freundlich isotherm } \\
\hline & $q m$ & $l$ & $R l$ & $R^{2}$ & $S D$ & $K f$ & $n f$ & $R^{2}$ & SD \\
\hline 2.50 & 0.862 & 0.050 & 0.166 & 0.950 & 0.634 & $5.91 \times 10^{-5}$ & 0.171 & 0.948 & 0.135 \\
\hline 4.50 & 0.476 & 0.017 & 0.370 & 0.955 & 3.660 & $2.33 \times 10^{-7}$ & 0.251 & 0.919 & 0.101 \\
\hline 6.50 & 0.341 & 0.016 & 0.384 & 0.966 & 2.777 & $2.09 \times 10^{-10}$ & 0.253 & 0.964 & 0.108 \\
\hline 8.50 & 0.190 & 0.012 & 0.454 & 0.907 & 5.275 & $1.57 \times 10^{-7}$ & 0.254 & 0.915 & 0.161 \\
\hline
\end{tabular}


Fig. 4 Characterization of S. cerevisiae (Meyen) biomass and AB 161 dye by FT-IR spectrophotometry

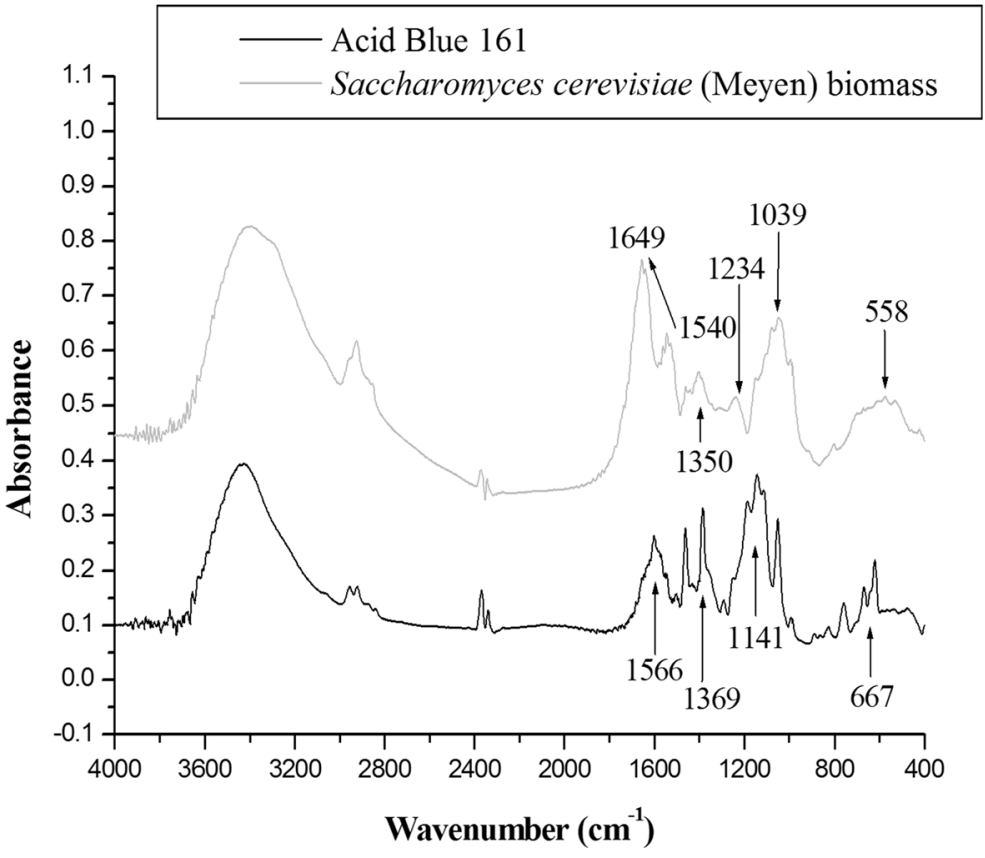

structure. The band at $1039 \mathrm{~cm}^{-1}$ had high intensity, indicating the presence of the $-\mathrm{C}-\mathrm{O}$ bond. This chemical group is present in the sugars of the yeast cell wall. The $558 \mathrm{~cm}^{-1}$ region demonstrated reasonable intensity, indicating the presence of the $-\mathrm{C}-\mathrm{N}-\mathrm{C}$ group found in proteins on the yeast cell wall.

The dye showed intensive bands in the 1369 and $1141 \mathrm{~cm}^{-1}$ regions, which correspond to $-\mathrm{C}=\mathrm{C}-$ and $\mathrm{C}-\mathrm{H}$ binding in aromatic rings. Another band with a high peak was in the $1566 \mathrm{~cm}^{-1}$ region, indicating the presence of an $-\mathrm{N}=\mathrm{N}-$ azo bond, which is typical of textile dyes. The peak at $667 \mathrm{~cm}^{-1}$ is the stretching of the $=\mathrm{C}-\mathrm{C}$ link in aromatic rings. All intensive regions of the dye spectrum correspond to their molecular structure (Fig. 5).

The FT-IR readings after biosorption at more acidic and more alkaline $\mathrm{pH}$ values demonstrated certain differences in the spectra (Fig. 6). FT-IR is a useful tool for identifying possible adsorptions links and confirming<smiles>O=S(=O)(O)c1cccc2c(/C=N/c3c(O)ccc4ccccc34)c(O)ccc12</smiles>

Fig. 5 Structure of Acid Blue 161 dye whether adsorption occurs through a chemical or physical process (Monash and Pugazhenti 2009).

A noticeably further intensification of certain bands in the spectrum of both biomasses was found after biosorption. The peak at $1651 \mathrm{~cm}^{-1}$ maintained the same pattern in all spectra, with greater intensification of the biomass in acidic $\mathrm{pH}$, indicating the presence of the $\mathrm{C}=\mathrm{O}$ bond. With the peak at $1548 \mathrm{~cm}^{-1}$, one can see some change in the region as well as further intensification. This region represents the deformation of the $-\mathrm{N}-$ $\mathrm{H}$ bond, indicating possible interaction with the dye. The band at $1428 \mathrm{~cm}^{-1}$ shows a distinct difference between the biomass in acidic $\mathrm{pH}$ and the other two conditions analyzed. Comparing the biomass in alkaline $\mathrm{pH}$ with biomass prior to biosorption, further intensification of the peak is seen, but the larger change in the spectrum band occurred in acidic $\mathrm{pH}$. This region represents a stretch of the $-\mathrm{C}-\mathrm{N}$ connection and is one of the probable chemical bonding points with the dye.

The peaks at 1074 and $1044 \mathrm{~cm}^{-1}$ constituted another point at which change occurred only in acidic $\mathrm{pH}$, indicating a change in the amino group $-\mathrm{C}-\mathrm{NH}_{2}-$. This region refers mainly to chitin present in yeast cell wall, which must be protonated due to the acidic $\mathrm{pH}$, strengthening the ionic bond with the sulfonic group of the dye. Another change to the spectrum of the biomass in acidic $\mathrm{pH}$ is seen in the $987 \mathrm{~cm}^{-1}$ band. This band is associated with sugars in the yeast cell wall, which 
Fig. 6 FT-IR spectrum of S. cerevisiae (Meyen) biomass before and after biosorption

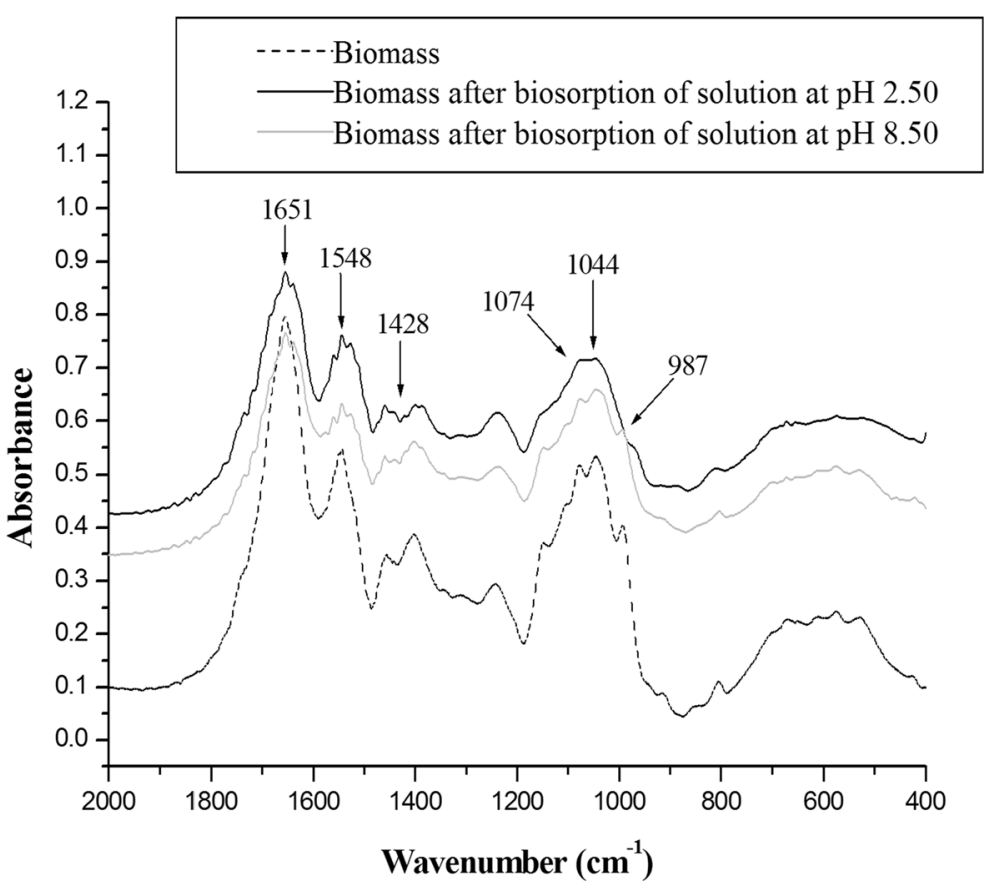

altered their initial structure due to the $\mathrm{pH}$ of the solution or some interaction with the dye molecule.

Considering the similarity of the biomass spectra before and after biosorption in alkaline $\mathrm{pH}$, physical adsorption is likely (Ngah et al. 2006), with the possible adsorption of hydrogen bonds or adsorption due to van der Waals forces, thereby confirming the data obtained with the Freundlich isotherm. The FT-IR spectra also demonstrate the chemical interaction between the dye and $S$. cerevisiae (Meyen) biomass in acidic $\mathrm{pH}$, confirming the results of the kinetic studies and isotherms. Based on the findings, a diagram was made of chitin as the major binding site with the dye (Fig. 7).

Other connections may occur more weakly at different sites in the cell wall of $S$. cerevisiae (Meyen), but the FT-IR spectra demonstrate that the principal binding was chitin, which is likely the main group involved in the sorption of dye molecules.

\subsection{Toxicity Test with $A$. salina}

The microcrustacean $A$. salina exhibited considerable sensitivity to the change in dye concentration in the solution. $\mathrm{LC}_{100}$ was $2850 \mu \mathrm{g} \mathrm{mL}^{-1}$, and $\mathrm{LC}_{50}$ was $2200 \mu \mathrm{g} \mathrm{mL}^{-1}$. Despite the high concentration of the dye, small amounts of biomass were sufficient to remove the toxicity of the solution either partially or completely (Table 4).
No toxicity decrease was observed with $100 \mathrm{mg}$ of biomass. However, $500 \mathrm{mg}$ of biomass was able to remove $472.16 \mu \mathrm{g} \mathrm{mL}^{-1}$ of the dye, reducing the

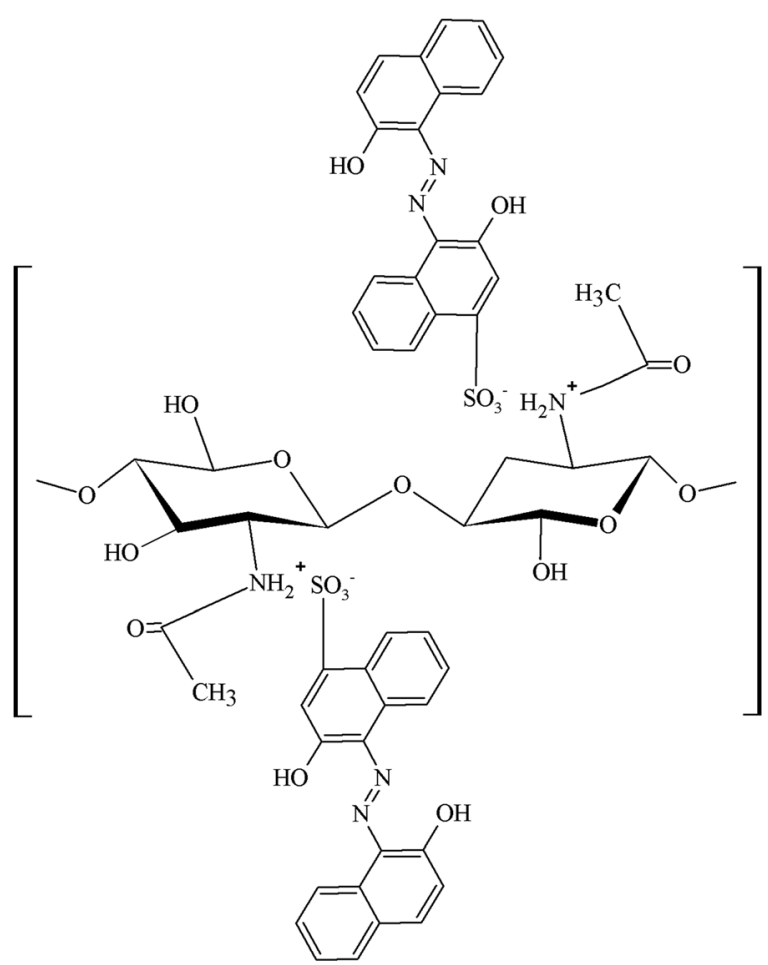

Fig. 7 Possible structure of chemical bond between chitin and AB 161 dye 
Table 4 Data from toxicity test with A. salina before and after biosorption

\begin{tabular}{llllr}
\hline & $\begin{array}{l}\text { Initial dye concentration } \\
\mathrm{LC}_{50}\left(\mu \mathrm{g} \mathrm{mL}^{-1}\right)\end{array}$ & $\begin{array}{l}\text { Final dye concentration } \\
\left(\mu \mathrm{g} \mathrm{mL}^{-1}\right)\end{array}$ & $\begin{array}{l}\text { Mortality } \\
(\%)\end{array}$ & $\mathrm{SD}$ \\
\hline Control & 2200.00 & 2200.00 & 50 & 3.467 \\
$100 \mathrm{mg}$ of biomass & 2200.00 & 2132.30 & 48 & 2.525 \\
$500 \mathrm{mg}$ of biomass & 2200.00 & 1772.84 & 29 & 2.804 \\
$1000 \mathrm{mg}$ of biomass & 2200.00 & 1097.20 & 10 & 4.976 \\
\hline
\end{tabular}

toxicity of the solution by $29 \%$. The highest dry yeast biomass $(1000 \mathrm{mg})$ led to the decrease of more than half of the dye concentration, nearly nullifying all toxicity.

Although the $\mathrm{pH}$ and temperature of the solution were not ideal for the biosorption process, the results were satisfactory. The biosorption using a microbial biomass of S. cerevisiae (Meyen) was an effective and viable alternative for the treatment of effluents contaminated with dyes, leading to the removal of both coloration and toxicity from the solution.

\section{Conclusion}

The dead biomass of S. cerevisiae (Meyen) demonstrated considerable sorption capacity of AB 161 dye, reaching the sorption equilibrium quickly and retaining large amounts of dye. The kinetic studies demonstrated the occurrence of intraparticle diffusion of the dye molecules in the yeast biomass, which is the controller of the biosorption process. It can therefore be concluded that AB 161 dye has a high affinity for the yeast cell wall.

The isotherm studies demonstrated that biosorption best fit the Langmuir model at all $\mathrm{pH}$ values, except $\mathrm{pH} 8.50$, indicating the occurrence of monolayers and a strong chemical interaction with the dye at a specific site. The isotherms also showed that more alkaline $\mathrm{pH}$ led to a lower sorption capacity of the $S$. cerevisiae (Meyen) biomass. Thus, $\mathrm{pH}$ is a critical factor for biosorption by exerting an influence on the affinity between the yeast cell wall and dye.

The thermodynamic studies indicate that several different sites of the yeast cell wall contributed to the sorption process, with predominantly stronger sorption at a specific site. The results also indicate that biosorption is an endothermic, spontaneous process that occurs naturally. Moreover, temperature exerted a direct influence on biosorption, with a more efficient process achieved at higher temperatures.
The FT-IR spectrophotometric results showed that physical adsorption occurred at $\mathrm{pH} 8.50$, whereas chemisorption occurred at $\mathrm{pH} 2.50$, thereby confirming the results of the kinetic, thermodynamic, and isotherm studies. The FT-IR results also indicate that chitin is the major site of interaction between the yeast cell wall and dye.

The microcrustacean A. salina proved to be a good indicator of the toxicity of the dye, exhibiting a considerable degree of sensitivity. The toxicity tests demonstrated that dye removal through biosorption by the yeast biomass lowered the toxicity of the solution, as evidenced by the decreased mortality rate of A. salina. With the removal of more than half of the $\mathrm{LC}_{50}$ concentration, the mortality of $A$. salina was nearly completely ceased, thereby demonstrating the efficiency of dye and toxicity removal by dead S. cerevisiae (Meyen) biomass.

Acknowledgments This study received funding from the Brazilian fostering agency Coordination for the Improvement of Higher Education Personnel (CAPES).

\section{References}

Almeida, E. J. R., \& Corso, C. R. (2014). Comparative study of toxicity of azo dye Procion Red MX-5B following biosorption and biodegradation treatments with the fungi Aspergillus niger and Aspergillus terreus. Chemosphere, 112, 317-322.

Annadurai, G., Ling, L. Y., \& Lee, J. F. (2008). Adsorption of reactive dye from an aqueous solution by chitosan: isotherm, kinetic and thermodynamic analysis. Journal of Hazardous Materials, 152, 337-346.

Araujo, J. C., Assis, J. T., Monine, V. I., \& Bertolino, L. C. (2006). Characterization of kaolinite microstructure by $\mathrm{X}$ ray diffraction. Materia (Rio de Janeiro), 11, 361-371.

Aravindhan, R., Rao, J. R., \& Nair, B. U. (2007). Removal of basic yellow dye from aqueous solution by sorption on green algae Caulerpa scalpelliformis. Journal of Hazardous Materials, $142,68-76$

Attia, A. A., Girgis, B. S., \& Fathy, N. A. (2008). Removal of methylene blue by carbons derived from peach stones by $\mathrm{H}_{3} \mathrm{PO}_{4}$ activation: batch column studies. Dyes and Pigments, 76, 282-289. 
Behnajady, M. A., Vahid, B., Modirshahla, N., \& Shokri, M. (2006). Evaluation of electrical energy per order $\left(\mathrm{E}_{\mathrm{EO}}\right)$ with kinetic modeling on photooxidative degradation of C.I. acid orange 7 in a tubular continuous-flow photoreactor. Industrial \& Engineering Chemistry Research, 45, 553-557.

Boyd, G. E., Adamson, A. W., \& Myers, L. S. (1947). The exchange adsorption of ions from aqueous solution by organic zeolites, II, Kinetics. Journal of the American Chemical Society, 69, 2836-2848.

Farah, J. Y., El-Gendy, N. S., \& Farahat, L. A. (2007). Biosorption of astrazone blue basic dye from an aqueous solution using dried biomass of Baker's yeast. Journal of Hazardous Materials, 148, 402-408.

Fat'hi, M. R., Asfaram, A., Hadipour, A., \& Roosta, M. (2014). Kinetics and thermodynamics studies for removal of acid blue 129 from aqueous solution by almond shell. Journal of Environmental Health Science \& Engineering, 12, 62.

Freundlich, H. (1906). Adsorption in solution. Zeitschrift für Physikalische Chemie, 40, 1361-1368.

Ghazi Mokri, H. S., Modirshahla, N., Behnajady, M. A., \& Vahid, B. (2015). Adsorption of C.I. Acid Red 97 dye from aqueous solution onto walnut shell: kinetics, thermodynamics parameters, isotherms. International Journal of Environmental Science and Technology, 12, 1401-1408.

Gholizadeh, A., Kermani, M., Gholami, M., \& Farzadkia, M. (2013). Kinetic and isotherm studies of adsorption and biosorption processes in the removal of phenolic compounds from aqueous solutions: comparative study. Journal of Environmental Health Science \& Engineering, 11, 29.

Gong, R., Zhang, X., Liu, H., Sun, Y., \& Liu, B. (2007). Uptake of cationic dyes from aqueous solution by biosorption onto granular kohlrabi peel. Bioresource Technology, 98, 1319-1323.

Guerra, D. L., \& Airoldi, C. (2009). The performance of ureaintercalated and delaminated kaolinites-adsorptions kinetics involving cooper and lead. Journal of the Brazilian Chemical Society, 1, 1-12.

Ho, Y. S., \& McKay, G. (1998). Sorption of dye from aqueous solution by peat. Chemical Engineering Journal, 70, 115-124.

Immich, A. P. S., Souza, A. A. U., Guelli, S. M. A., \& Souza, U. (2009). Removal of remazol blue RR dye from aqueous solutions with neem leaves and evaluation of their acute toxicity with Daphnia magna. Journal of Hazardous Materials, 164, 1580-1585.

Jadhav, J. P., Phugare, S. S., Dhanve, R. S., \& Jadhav, S. B. (2010). Rapid biodegradation and decolorization of direct orange 39 (orange TGLL) by an isolated bacterium Pseudomonas aeruginosa strain BCH. Biodegradation, 21, 453-463.

Lagergren, S. (1898). Zur theorie der sogenannten adsorption gel oster stoffe. Kung-liga Svenska Vetenskapsakademiens. Handlingar, 24, 1-39.

Langmuir, I. (1918). The adsorption of gases on plane surface of glass, mica and platinum. Journal of the American Chemical Society, 40, 1361-1368.

Li, G., Jiang, Y., Huang, K., Ding, P., \& Yao, L. (2008). Kinetics of adsorption of Saccharomyces cerevisiae mandelated dehydrogenase on magnetic $\mathrm{Fe}_{3} \mathrm{O}_{4}$-chitosan nanoparticles. Colloids and Surfaces A, 320, 11-18.

Lipke, P. N., \& Ovalle, R. (1998). Cell wall architecture in yeast: new structure and new challenge. Journal of Bacteriology, 180, 3735-3740.
McKay, G., Blair, H. S., \& Gardner, J. R. (1982). Adsorption of dyes on chitin: equilibrium studies. Journal of Applied Polymer Science, 27, 3043.

Monash, P., \& Pugazhenti, G. (2009). Adsorption of crystal violet dye from aqueous solution using mesoporous materials synthesized at room temperature. Adsorption, 15, 390-405.

Ngah, W. S. W., Kamari, A., Fatinathan, S., \& Ng, P. W. (2006). Adsorption of chromium from aqueous solution using chitosan beads. Adsorption, 12, 249-257.

Parra, A. L., Yhebra, R. S., Sardiñas, I. G., \& Buela, L. I. (2001). Comparative study of the assay of Artemia salina and the estimate of the medium lethal dose $\left(\mathrm{LD}_{50}\right.$ value) in mice, to determine oral acute toxicity of plant extracts. Phytomedicine, 8, 395-400.

Podkoscielny, P., \& Nieszporek, K. (2011). Adsorption of phenols from aqueous solutions: equilibria, calorimetry and kinetics of adsorption. Journal of Colloid and Interface Science, 354, 282-291.

Priya, E. S., Selvan, P. S., \& Umayal, A. N. (2015). Biodegradation studies on dye effluents and selective remazol dyes by indigenous bacterial species through spectral characterization. Desalination and Water Treatment, 55, 241-251.

Saber-Samandari, S., \& Heydaripour, J. (2015). Onion membrane: an efficient adsorbent for decoloring of wastewater. Journal of Environmental Health Science \& Engineering, 13, 16.

Safariková, M., Ptcáková, L., Kibriková, I., \& Safariki, I. (2005). Biosorption of water-soluble dyes on magnetically modified Saccharomyces cerevisiae subsp. Uvarum cells. Chemosphere, 59, 831-835.

Sharma, P., Kaur, H., Sharma, M., \& Sahore, V. (2011). A review on applicability of naturally available adsorbents for the removal of hazardous dyes from aqueous waste. Environmental Monitoring and Assessment, 183, 151-195.

Singh, K. P., Mohan, D., Sinha, S., Tondon, G. S., \& Gosh, D. (2003). Color removal from wastewater using low-cost activated carbon derived from agricultural waste material. Industrial \& Engineering Chemistry Research, 42, 1965-1976.

Srinivasan, A., \& Viraraghavan, T. (2010). Decolorization of dye wastewaters by biosorbents: a review. Journal of Environmental Management, 91, 1915-1929.

Suteu, D., Blaga, A. C., Diaconu, M., \& Malutan, T. (2013). Biosorption of reactive dye from aqueous media using Saccharomyces cerevisiae biomass. Equilibrium and kinetic study. Central European Journal of Chemistry, 11, 2048-2057.

Toor, A. P., Verma, A., Jotshi, C. K., Bajpai, P. K., \& Singh, V. (2006). Photocatalytic degradation of direct yellow 12 dye using UV/TiO, in a shallow pond slurry reactor. Dyes and Pigments, 68, 53-60.

Varó, I., Serrano, R., Navarro, J. C., López, F. J., \& Amat, F. (1998). Acute lethal toxcity of the organophosphorous chlorpyrifos to different species and strains of Artemia. Bulletin of Environmental Contamination and Toxicology, 61, 778-785.

Vitor, V., \& Corso, C. R. (2008). Decolorization of textile dye by Candida albicans isolated from industrial effluents. Journal of Industrial Microbiology and Biotechnology, 35, 13531357.

Weber, W. J., \& Morris, J. C. (1963). Kinetics of adsorption on carbon from solution. Journal of the Sanitary Engineering Division, 89, 31-60. 